\title{
Peroxidases of Seeds of the Soy Genetic Collection
}

\author{
Shavkat Yunusxanov', Mirzohid Sh. Jaynaqov² \\ ${ }^{1}$ Institute of genetics and plant experimental biology Academy Science Republic of Uzbekistan, Tashkent, Uzbekistan \\ ${ }^{2}$ Andijan state University, Andijan, Uzbekistan \\ Email:bio_jaynaqov@mail.ru
}

How to cite this paper: Yunusxanov, S. and Jaynaqov, M.Sh. (2020) Peroxidases of Seeds of the Soy Genetic Collection. American Journal of Plant Sciences, 11, 549-553. https://doi.org/10.4236/ajps.2020.114039

Received: March 8, 2020

Accepted: April 20, 2020

Published: April 23, 2020

Copyright (c) 2020 by author(s) and Scientific Research Publishing Inc. This work is licensed under the Creative Commons Attribution International License (CC BY 4.0).

http://creativecommons.org/licenses/by/4.0/

\begin{abstract}
The article studies the activity of the peroxidase enzyme in cereals and barks of some varieties of soy plants. The soy (plant) samples we studied were obtained in the conditions of the Tashkent region at the experimental field of the Institute of genetics and plant experimental biology in the village of Durmen. 11 samples out of 40 examined on electrophoregrams did not show the presence of the studied enzymes. Further research is needed to clarify the results.
\end{abstract}

\section{Keywords}

Peroxidase, Soy, Genetic, Collection, Seeds

\section{Introduction}

Peroxidase is polyfunctional, heterogeneous in isozymic composition and undergoes significant variability under adverse environmental conditions [1]. V. A. Andreeva [2] presents literature data that peroxidase is associated with a number of metabolic transformations occurring in cells within the $\mathrm{pH}$ range from 3 to 14. It was found that the enzyme has not only peroxidase, but also oxidase properties, catalyzing the oxidation of a number of compounds.

Peroxidase is activated in many changes and disorders of plant metabolism, and some isozymes are synthesized de novo in response to stress. The existence of peroxidase isozymes with different activity, but identical in relative electrophoretic mobility, was shown by methods of electrophoresis and electrofocusing. What has both peroxidase and o-difenoconazol activity was noted in works [3] [4]. It is proposed to use peroxidases as a diagnostic sign for assessing the degree of plant resistance to stress factors [5]. 
In recent years, the agro-industrial complex of the Republic of Uzbekistan has paid special attention to further increasing the volume of seeding and cultivation of soybeans to better meet the needs of the population in vegetable oil, livestock and poultry farms-in nutritious feed, as well as the effective use of production capacities of processing enterprises. In this regard, the creation of new high-yielding and promising soybean varieties and comprehensive research in the field of biochemistry, physiology and genetics of this crop are relevant.

Such studies have not been carried out on a national scale to date. At the Institute of genetics and plant experimental biology Academy Science Republic of Uzbekistan, Prof. M. F. Abzalov created a genetic collection of soybeans under the names from Gen-1 to Gen-40 on the basis of collection samples from the Institute of crop production and the rice Institute of Uzbekistan [6]. The origin of these specimens is mainly from European countries, the United States of America and Australia.

Previously, the protein content and oil content of seeds were studied on 24 samples of the soy collection and it was shown that the total protein content in soy seeds ranges from $17.4 \%$ (Gen-20) to $28.6 \%$ (Gen-17), and the oil content from $18 \%$ to $27 \%$ [4]. Further, when studying the isoenzyme composition of peroxidase and O-diphenol oxidase in the seeds of samples from Gen-1 to Gen-40 of the same collection for the purpose of biochemical labeling, it was found that the studied samples were divided into two groups based on the presence of both enzymes: one group contained peroxidase and O-diphenol oxidase with the same electrophoretic mobility, and in the other group, consisting of 11 samples, both groups of enzymes were absent [4].

It is known that peroxidase is an enzyme that provides the body with protective functions against various stress factors [1] [2] [5]. In this regard, further work was devoted to the study of water extract of fat-free and non-fat seeds, as well as seed shells of soy collection samples that did not contain peroxidases.

\section{Research Objects and Methods}

Soy seeds were separated from the shell using a scalpel. The obtained samples of seeds and shells were crushed in a porcelain mortar to a fine flour, after which they were divided into two parts and one part of them was degreased with ethyl ether in the Sok-Sleta apparatus. The flour suspension of the obtained samples was extracted with distilled water in the ratio flour:water 1:10 for 1 hours. Flour extracts were centrifuged at $6000 \mathrm{rpm}$ for 30 minutes and subjected to electrophoretic separation in an alkaline gel [7]. Gel after electrophoresis and paper filters with applied extracts were stained for the presence of peroxidase by the method [8].

\section{Result and Discussion}

Usually, skimmed soy seed flour was used to isolate protein fractions and study their electrophoretic composition. During electrophoresis of an aqueous extract 
from non-fat flour, a manifestation of peroxidase was detected in the start area. In this regard, further experiments on the detection of peroxidase were performed on chromatographic or filter paper.

To do this, 5 - $8 \mathrm{mkl}$ of water extract of seeds and soybean seed coats were applied to paper and the peroxidase manifestation was performed using the method [8]. In the literature, there is evidence of high peroxidase activity in soybean seed coats [9], in connection with which we have studied extracts of seed coats. The data obtained are shown in Figure 1, and a visual description of their quantitative content in Table 1.

It was found that peroxidase activity in soybean seed coats (Clycine max LI Merr.) is controlled by the Eplocus [9].

It is shown that in soybean seed coats of the EpEp genotype, peroxidase activity is 100 times higher than that of epep genotype varieties.

Based on these data, we can assume that the soy samples we studied differ from each other in the state of loci that control peroxidase activity. Electrophoretic study of peroxidase from seed extracts and seed coats revealed one main

\begin{tabular}{|ccc|ccc|}
\hline & Flour & & \multicolumn{3}{c|}{ Coat } \\
Gen-1 & Gen-3 & Gen-17 & Gen-1 & Gen-3 & Gen-17 \\
Gen-20 & Gen-26; & Gen-27 & Gen-20 & Gen-26 & Gen-27 \\
& & & & & \\
Gen-34 & Gen-35: & Gen-36 & Gen-34 & Gen-35 & Gen-36 \\
& & & & & \\
Gen-37 & & & & & \\
& & & Gen-37 & Gen-39 & \\
\hline
\end{tabular}

Figure 1. The presence of peroxidase activity in the aqueous extract of non-fat flour and seed shells of soy collection samples.

Table 1. Peroxidase content in extracts of non-fat flour seeds and seed coats of the soy genetic collection (visual assessment in points is presented).

\begin{tabular}{cccccc}
\hline Sample & $\begin{array}{c}\text { Seed flour } \\
\text { extract }\end{array}$ & $\begin{array}{c}\text { Seed coat } \\
\text { extract }\end{array}$ & Sample & $\begin{array}{c}\text { Seed flour } \\
\text { extract }\end{array}$ & $\begin{array}{c}\text { Seed coat } \\
\text { extract }\end{array}$ \\
\hline Gen-1 & 2 & 0 & Gen-34 & 2 & 0 \\
Gen-3 & 2 & 5 & Gen-35 & 1 & 0 \\
Gen-17 & 0 & 0 & Gen-36 & 1 & 0 \\
Gen-20 & 0.5 & 4 & Gen-37 & 1 & 0 \\
Gen-26 & 0 & 4 & Gen-39 & 0 & 5 \\
Gen-27 & 0 & 4 & & & \\
\hline
\end{tabular}


band with an electrophoretic mobility of 0.56 , as well as two minor bands with a mobility of 0.47 to 0.51 , and no significant differences were found between them. The paper [9] also shows the identity of soybean seed coat peroxidase with the EpEp genotype with root peroxidase, which was proved by isoelectric focusing of extracts.

As can be seen from the presented data extracts from the flour of the seeds and seed shells differ in peroxidase activity. Extracts from seed flour of gen-17, Gen-26, Gen-27 samples and extracts of seed coats of Gen-1, Gen-34, Gen-35, Gen-37 samples show weak brown staining, which may be due to the presence of other forms of isoperoxidases in them. Intense peroxidase staining was observed in extracts from the seed coats of Gen-3, Gen-20, Gen-26, Gen-27, and Gen-39 samples. No peroxidase activity was detected in extracts from skimmed seed flour, and only samples of Gen-3, Gen-26, and Gen-27 showed peroxidase activity in extracts of seed coats.

\section{Conclusion}

Literature data indicate that the content of peroxidase in soybean seeds strongly depends on cultivars and agroecological conditions, as well as the year of cultivation [10] [11] [12]. The soy samples we studied were obtained in the conditions of the Tashkent region at the experimental field of the Institute of plant genetics and experimental biology in the village of Durmen. 11 samples out of 40 examined on electrophoregrams did not show the presence of the studied enzymes. Further research is needed to clarify the results.

\section{Conflicts of Interest}

The authors declare no conflicts of interest regarding the publication of this paper.

\section{References}

[1] Kartashova, E.R., Rudenskaya, G.N. and Yurina, E.V. (2000) Polyfunctionality of Plant Peroxidases and Their Practical Use. Plant Biology, 5, 63-70. https://doi.org/10.1626/jcs.84.69

[2] Andreeva, V.A. (1988) Enzyme Peroxidase: Participation in the Protective Mechanism of Plants. Nauka, Moscow, $128 \mathrm{p}$

[3] Yunusxanov, S., Kurbanbayev, I.D., Abdurazakova, Z.L., Khazratkulov, S.A. and Boymatov, B.U. (2014) Electrophoretic Spectrum of Peroxidase and o-Diphenol Oxidase Isozymes of Cotton Seeds. Uzbek Biological Journal, 3, 62-65. https://doi.org/10.1007/s11104-012-1335-Z

[4] Yunusxanov, Sh., Jaynaqov, M., Abzalov, M.F., Kurbanbayev, I.D. and Abdurazakova, Z.L. (2019) Electrophoretic Analysis of Peroxidase and o-Diphenoloxidase of Seeds of the Genetic Collection of Soy. Report Academy of Sciences of Uzbekistan, 2, 90-93. https://doi.org/10.1016/j.carbpol.2010.07.066

[5] Smith, H.H., Hamill, D.E., Weaver, E.A. and Thompson, K.H. (1970) Multiple Molecular Forms of Peroxidases and Esterases among Nicotiana Species and Amphiploids. Journal of Heredity, 61, 203-212. 
https://doi.org/10.1111/j.1750-3841.2007.00607.x

[6] Abzalov, M.F. and Kilicheva, O.B. (2008) Genetic Collection of Soy Plants Institute of Genetics and Plant Experimental Biology. Academy Science Republic of Uzbekistan Report, Academy of Sciences of Uzbekistan, 77-80.

[7] Yunusxanov, Sh. (1973) Isolation and Investigation of the Chemical Composition of the Proteins of Cotton. In the Collection: Methods of Physiological and Biochemical Studies of Cotton. Tashkent, 28-54.

[8] Safonov, V.I. and Safonova, M.P. (1971) Research of Proteins and Enzymes Application of Electrophoresis Methods in Polyacrylamide Gel. Biochemical Methods in Plant Physiology. Science, 113-121.

[9] van Huystee, C.R. and Buzzell, R. (1993) Soybean Seed Coat Peroxidase Acomparison of High-Activity and Low-Activity Genotypes. Mark Plant Physiology, 103, 1061-1066.

[10] Semenova, E.A. (2012) Influence of Water Stress on the Activity and Electrophoretic Spectra of Antioxidant Enzymes in Soy Seeds. Modern Science-Intensive Technologies, 7, 33-35. https://doi.org/10.1016/j.scienta.2015.09.021

[11] Ivachenko, L.E., Egorova, I.V. and Fomenko, N.D. (2010) Characteristics of Electrophoretic Spectra of Enzymes as Markers of Soybean Varieties. International Journal of Applied and Fundamental Research, 5, 65-69. https://doi.org/10.1093/pcp/pcq086

[12] Ivachenko, L.E. (2010) The Role of Multiple Forms of Soy Enzymes in the Process of Biochemical Adaptation to Growing Conditions. Success of Modern Natural Science, 9, 96-98. 